\title{
Apexoconnection: A Novel Technique to Determine Working Length
}

\author{
Muslat A Bin Rubaia'an (D) \\ Mohammed AbuHassna ${ }^{2}$ \\ Rahaf K AIShahrani (iD) \\ Khaled Alghulikah (D) ${ }^{2}$ \\ Abdulrahman Dahham Alsaffan ${ }^{3}$ \\ 'College of Dentistry, Riyadh Elm \\ University, Riyadh, Kingdom of Saudi \\ Arabia; ${ }^{2}$ Restorative Dentistry \\ Department, College of Dentistry, Riyadh \\ Elm University, Riyadh, Kingdom of Saudi \\ Arabia; ${ }^{3}$ Preventive Dentistry \\ Department, College of Dentistry, Riyadh \\ Elm University, Riyadh, Kingdom of Saudi \\ Arabia
}

Purpose: The aim of this study was to evaluate and compare the accuracy of working length (WL) determination when using the conventional electronic WL (EWL) technique versus using the novel Apexoconnection technique involving EWL with a connector (EWLc).

Materials and Methods: Sixty extracted posterior teeth with a total of 118 root canals were selected for the study. The real WL (RWL) of each canal was verified using a dental microscope under 25.6x magnification. Root canal lengths were measured with an apex locator using the attachment device directly attached to the hand file in the root canal and then adding another hand file as a connector between the attachment device and the file in the root canal. The distance from the file's stopper to its tip was measured using a digital caliper. Statistical analysis was carried out to analyze the data between experimental groups.

Results: The results of the statistical test showed that the differences in the WL determined by either technique and the proper length as determined under the microscope were not statistically significant. The results of the statistical test comparing the groups were also not statistically significant.

Conclusion: In this in vitro study, both the novel and conventional techniques were equally accurate for determining WL when compared with the RWL.

Keywords: electronic apex locator, electronic working length, endodontics, root canal treatment, working length determination

\section{Introduction}

One of the goals of endodontic treatment is to maintain or restore the health of periradicular tissues by ensuring adequate cleaning and shaping of the root canal system. ${ }^{1,2}$ Hence, treatment success is defined by factors, such as the correct determination of root canal working length (WL). ${ }^{3}$ The WL is the interspace between two reference points: (1) One point is located coronally and (2) the other point is located at the terminal in which the canal preparation and obturation terminate. ${ }^{4}$ Preferably, the cementodentinal junction (CDJ) should be considered as the point at which the obturation ends; however, it is impossible to clinically identify this histological structure. The position of the $\mathrm{CDJ}$ is highly variable from one tooth to another and even from one wall to the opposite wall of the same root. Therefore, the apical constriction (AC) is considered an acceptable terminus for canal preparation. ${ }^{5,6}$

Procedural errors and mishaps, such as over- or under-instrumentation, may occur because of inaccurate determination of the root canal WL, which causes a worse prognosis with respect to endodontic treatment. ${ }^{7,8}$ The possible injuries caused by overinstrumentation with enlargement of the AC include periradicular inflammation, postoperative pain, and injury to the periapical tissues, resulting in delayed or absence of
Correspondence: Muslat A Bin Rubaia'an Tel +966557020222

Email Mislat.BinRubayan@student.Riyadh. edu.sa 
healing processes. ${ }^{9,10}$ In contrast, under-instrumentation leaves parts of the root canal inadequately cleaned and contaminated with bacteria, which will affect the quality of the root canal filling and root canal treatment outcomes. ${ }^{5,11}$

In many studies, confinement to $\mathrm{AC}$ in instrumentation and obturation shows better histological outcomes has been reported. ${ }^{5,12,13}$ Therefore, accurate determination of the WL is crucial for successful endodontic treatment.

Several methods have been established for calculating the WL. These methods include the use of radiographs, anatomical identification, tactile sensation, and moisture on paper points. Using radiographs is the most common technique for WL determination. ${ }^{14}$ Radiographs aid in identifying the anatomy of the root canal, the number of roots, and the presence of lesions. ${ }^{15}$ The disadvantage of this method is not being able to determine the position of the $\mathrm{AC}$ by radiographs because of the internal morphology of the root canal. ${ }^{16,17} \mathrm{In}$ addition, many recent studies have proven the inaccuracy of the radiographic method. ${ }^{18}$ Dummer et al concluded that locating the AC clinically with certainty is impossible because of its position and topography. ${ }^{19}$

Electronic apex locators (EALs) have been introduced in endodontics for electronic WL (EWL) determination. EWLs use the human body for completion of an electrical circuit. ${ }^{20}$ This circuit is completed by attaching the apex locator's clip to the oral mucosa of the patient and a K-file or nickel titanium file (NiTi file) using the attachment device. ${ }^{3,20}$ Use of these files has become very common due to their highly accurate $\mathrm{AC}$ locating rates. They also significantly help in overcoming the drawbacks associated with radiographs. ${ }^{3,21}$ The accuracy of the EWL technique has been confirmed by several studies. ${ }^{17,22}$ Some studies have demonstrated that EWLs provide a more precise estimation of WL than do radiographs. ${ }^{17,23,24}$

In routine daily practice, a few problems, such as space limitations in which the attachment device metal shaft cannot be inserted, are commonly encountered with attachment device usage to calculate the EWL (Figure 1). In addition, the attachment device may not be capable of accessing the posterior teeth in cases in which short files are used. Moreover, a false-positive will result when the root canal treatment is performed for a tooth through a metal crown or amalgam restoration. ${ }^{25}$ These kinds of clinical obstacles result in difficulties and extended treatment times, which increases the overall costs. To overcome these limitations, many companies have introduced new attachments that can facilitate the insertion of a hand file. ${ }^{26}$ One such clinical technique that has been used by some practitioners to help eliminate these limitations uses a hand file as a connector between the attachment device and the file in the root canal. However, and to the best of our knowledge, this process has not been discussed or evaluated in the scientific literature.

Therefore, the aim of this study was to evaluate and compare the accuracy of WL determination when using the conventional technique (EWL) and when using a novel

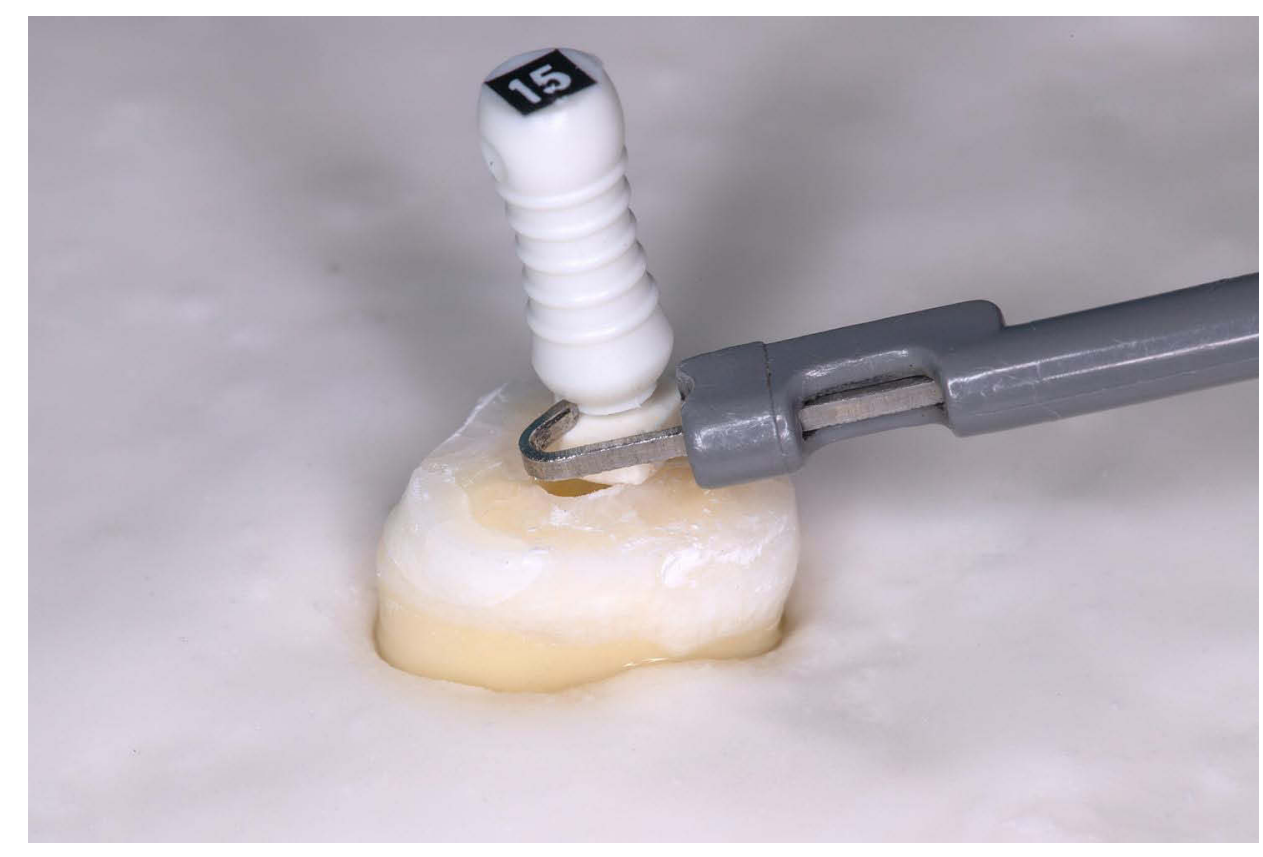

Figure I Limited space for conventional attachment device. 
Apexoconnection technique for calculating the EWL with a connector (EWLc) to solve any given problems. The null hypothesis states that no significant differences in length measurements between the EWL and EWLc approaches will be found, and all measurements will be within the clinically accepted margin of error of $\pm 0.5 \mathrm{~mm}$.

\section{Materials and Methods}

The study was registered in the Research Center of Riyadh Elm University and received ethical approval from the Institutional Review Board (number: FUGRP/2020/176). Written informed consent was obtained from all patients whose teeth were used in this study, in accordance with the Declaration of Helsinki.

\section{Teeth Selection and Preparation}

Sixty teeth (12 upper molars, 6 lower molars, 22 upper premolars, and 18 lower premolars) with a total of 118 canals of the roots of all teeth that had recently been extracted because of periodontal diseases or for orthodontic reasons, were selected. In order to reduce variables, teeth selection was based on various exclusion criteria (Table 1). ${ }^{8,14,21,27,28}$ Standardized pre-operative diagnostic periapical radiographs were taken for each tooth to confirm meeting these criteria. All teeth were placed in $2.5 \%$ sodium hypochlorite solution ( $\mathrm{NaOCl}$; Diaa, Saudi Arabia) for 2 hours to remove organic residues and then stored in sterile $0.9 \%$ saline solution (PSI, Saudi Arabia) until further use.

The teeth were numbered, and the occlusal surfaces were flattened using a wheel bur that provided a Flat surface perpendicular to the long axis of the roots to simplify obtaining the length measurements. Standard access preparations were performed, and the coronal portion of the canals was flared using \#2 and \#3 Gates-Glidden burs (MANI Inc., Tochigi, Japan) that allowed the file to reach the AC easily and facilitate WL determination. ${ }^{14,29} \mathrm{Next}$, the canals were irrigated with $5 \mathrm{~mL}$ of $2.5 \% \mathrm{NaOCl}$, and the patency of the

Table I Exclusion Criteria for Teeth Selection

Obvious caries
Coronal restorations
Resorptive defects
Curvatures
Open apices
Root canal obliteration
Perforation
Incomplete root formation

apical foramen was confirmed with a \#8 stainless steel K-file (MANI Inc., Tochigi, Japan). ${ }^{21}$ The major foramen of each root was reached by inserting a \#10 stainless steel K-file (MANI Inc., Tochigi, Japan) into the root canal to establish the actual root canal length (RL). Proper positioning was verified using a dental microscope (OMS 2350, Zumax, Jiangsu, China) under 25.6x magnification (Figures 2 and 3).

By reaching the apical foramen with the file tip, the silicone stopper was adjusted coronally. The distance from the file's stopper to its tip was measured using a digital caliper. The measurements were repeated twice by two operators, and the average was taken as the actual length (RL). The real WL (RWL) was established by subtracting $0.5 \mathrm{~mm}$ from the RL of the canal. Teeth were placed in plastic containers and embedded in alginate (Kromopan, Lascod, Florence, Italy) along with the lip clip of the apex locator with the aim of producing similar clinical conditions (Figure 4). ${ }^{30}$ To preserve and ensure the humidity of the alginate, all measurements were taken within 30 minutes of model preparation.

\section{Working Length Measurements}

Each root canal $(n=118)$ was measured using the attachment device directly attached to the hand file in the root canal and then using another hand file as a connector between the attachment device and the file in the root canal. Root canals were irrigated with $2.5 \% \mathrm{NaOCl}$. All of the manual mode $\mathrm{WL}$ measurements were performed according to the

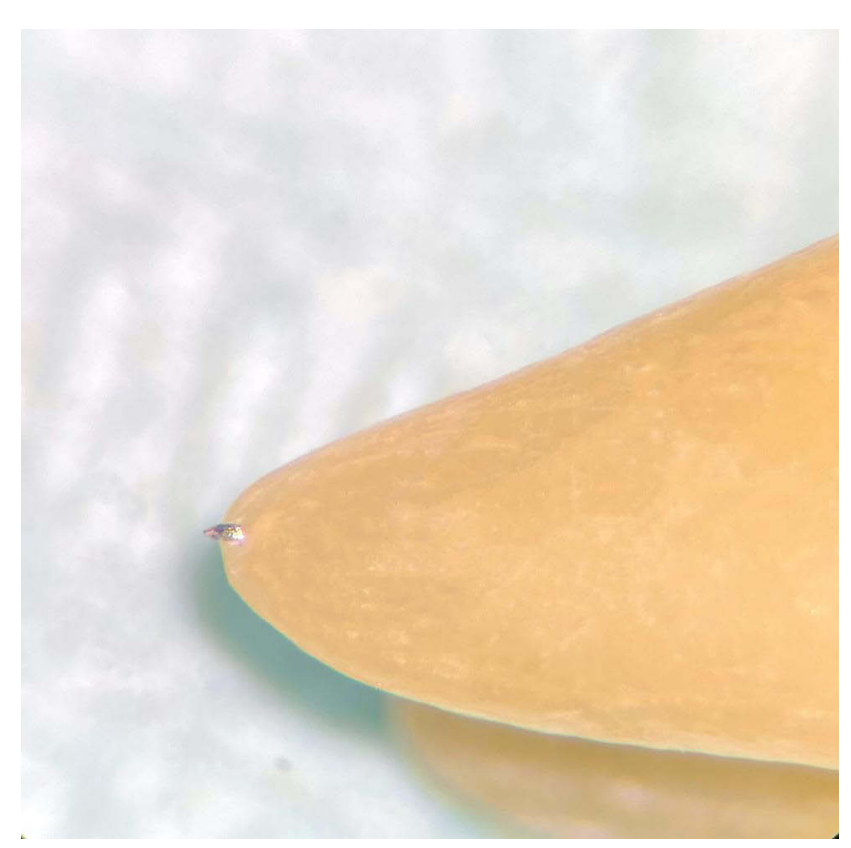

Figure $2 \mathrm{~K}$-file inserted into the root canal under the microscope, exceeding the apical foramen. 


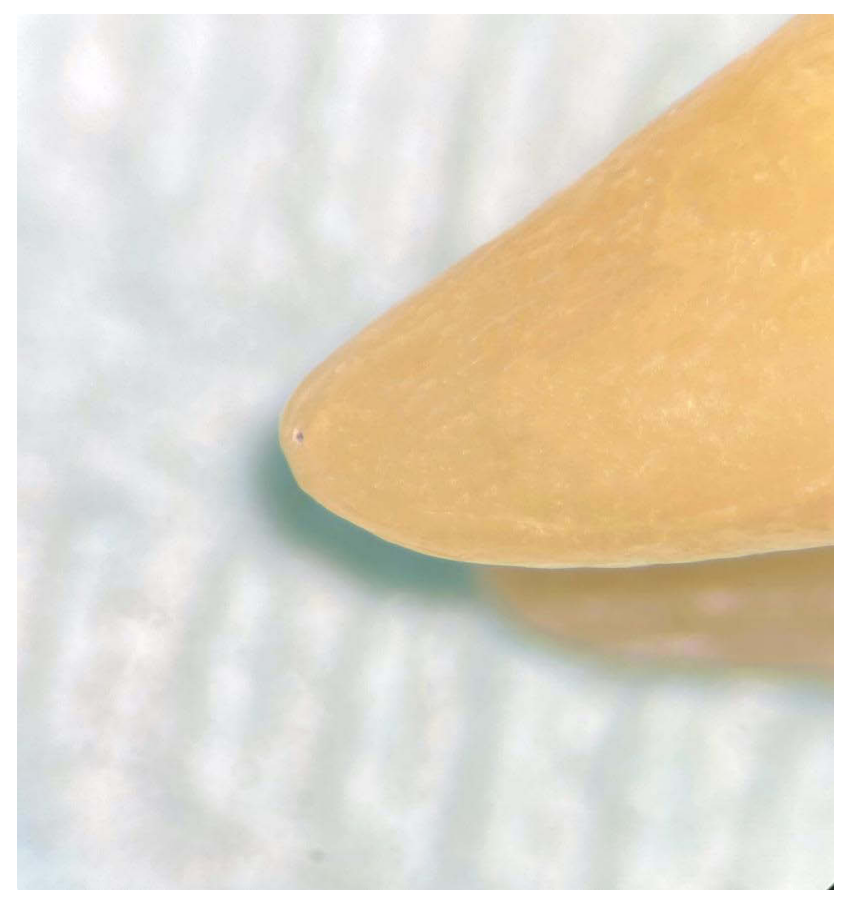

Figure 3 Under the microscope, the K-file was inserted into the root canal at the most cervical edge of the apical foramen.

manufacturer's instructions. ${ }^{27}$ The apex locator's (Denta Ports ZX, J. Morita MFG, CORP, Kyoto, Japan) attachment device was attached to a \#15 stainless steel K-file (MANI Inc., Tochigi, Japan). Within the root canal, the file was inserted to the apex point indicated by the apex locator device. The file was then withdrawn until the audible signal at the 0.5 point was heard, indicating that the AC had been reached. The measurements were considered valid if they were stable for
5 seconds or more. The distance from the file's stopper to its tip was measured using a digital caliper. A mean value of two measurements obtained from two operators was recorded for each canal as the EWL. The same procedure was carried out using a \#15 stainless steel K-file attached as a connector to the to the apex locator's attachment device to touch the \#15 stainless steel K-file that was within the root canal, and a mean value of two measurements obtained from two operators was recorded for each canal as the EWL using a connector (EWLc).

\section{Statistical Analysis}

A one-way analysis of variance (ANOVA) test was calculated to compare the readings for RWL, EWL, and EWLc. Statistical analyses were performed using Statistical Package for Social Sciences (IBM-SPSS version 25, Armonk, NY: USA). A value of $\mathrm{p}<0.05$ was considered significant for all the statistical analysis purposes.

\section{Results}

The result of the Cronbach's alpha test to determine interexaminer reliability was 0.97 , which was excellent. Tests of normality indicated normal distribution of the canal lengths among different groups data $(\mathrm{p}>0.05)$ as shown in (Table 2). The descriptive statistics of canal lengths measured using Microscope, EAL, and EALc are displayed in (Table 3). The mean WL obtained using the EWL at $17.88 \mathrm{~mm}$ and using the EWLc at $18.01 \mathrm{~mm}$ were comparable to the real working lengths determined under the endodontic microscope (RWL) at $17.98 \mathrm{~mm}$. The EWLc

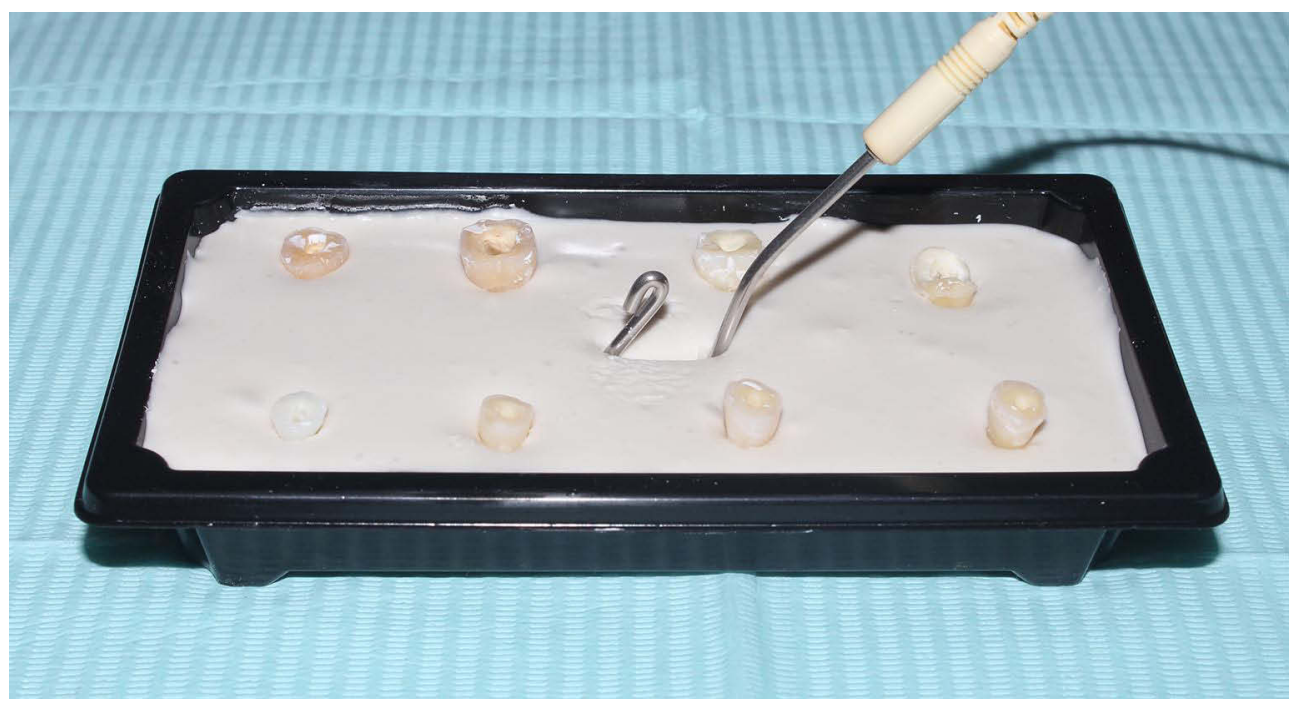

Figure 4 Alginate apparatus for electronic working length determination. 
Table 2 Normality Assessment of the Data Using Kolmogorov-Smirnov and Shapiro-Wilk's Tests

\begin{tabular}{|c|c|c|c|c|c|c|c|}
\hline \multirow[t]{2}{*}{ Canal Length } & \multirow[t]{2}{*}{ Groups } & \multicolumn{3}{|c|}{ Kolmogorov-Smirnov } & \multicolumn{3}{|c|}{ Shapiro-Wilk } \\
\hline & & Statistic & df & $\mathbf{p}$ & Statistic & df & $\mathbf{p}$ \\
\hline & RWL & 0.082 & 118 & 0.050 & 0.984 & 118 & 0.188 \\
\hline & EAL & 0.078 & 118 & 0.077 & 0.981 & 118 & 0.101 \\
\hline & EALc & 0.062 & 118 & $0.200 *$ & 0.978 & 118 & 0.050 \\
\hline
\end{tabular}

Note: ${ }^{*} \mathrm{p}>0.05$

Table 3 Statistics Values of Real Working Length and Length Determined by the Two Techniques

\begin{tabular}{|c|c|c|c|c|c|c|c|c|}
\hline \multirow{2}{*}{$\begin{array}{l}\text { Canal } \\
\text { Length }\end{array}$} & \multirow[t]{2}{*}{$\mathbf{N}$} & \multirow[t]{2}{*}{ Mean } & \multirow[t]{2}{*}{ SD } & \multirow[t]{2}{*}{ Std. Error } & \multicolumn{2}{|c|}{ 95\% Confidence Interval for Mean } & \multirow[t]{2}{*}{ Minimum } & \multirow[t]{2}{*}{ Maximum } \\
\hline & & & & & Lower Bound & Upper Bound & & \\
\hline RWL & 118 & 17.98 & 2.02 & 0.19 & 17.61 & 18.35 & 12.86 & 23.43 \\
\hline EAL & 118 & 17.88 & 1.95 & 0.18 & 17.53 & 18.24 & 13.1 & 23.05 \\
\hline EALc & 118 & 18.01 & 1.91 & 0.18 & 17.66 & 18.36 & 13.93 & 23 \\
\hline Total & 354 & 17.96 & 1.95 & 0.10 & 17.75 & 18.16 & 12.86 & 23.43 \\
\hline
\end{tabular}

measurement of the canal length was found to be nearer to that of the microscopic measurement of the canal length. However, a one-way ANOVA comparison of canal lengths using the microscope (RWL), the conventional technique (EWL), and Apexoconnection (EWLc) did not yield any statistically significant differences $(\mathrm{F}=0.133, \mathrm{p}=0.876)$ as shown in (Table 4). Tukey's post-hoc tests for the pairwise comparison of the mean canal length results indicated no statistically significant differences (Table 5).

\section{Discussion}

Accurate determination of WL is critical to the success of endodontic treatment. ${ }^{3}$ Overestimation of WL can cause delayed healing by injuring the periapical tissue, while WL underestimation may result in bacterial contamination, causing failure of the root canal treatment. ${ }^{3,11}$ Both over and underestimation of the WL can significantly jeopardize the prognosis of root canal treatment. ${ }^{7}$ Numerous generations of EALs are available for clinical use. However, the third

Table 4 Results of One-Way Analysis of Variance (ANOVA) Test

\begin{tabular}{|l|r|r|r|r|r|}
\hline & \multicolumn{1}{|c|}{ Sum of Squares } & df & Mean Square & F & P \\
\hline Between Groups & 1.019 & 2 & 0.509 & 0.133 & \\
Within Groups & 1346.775 & 351 & 3.837 & \\
Total & 1347.793 & 353 & & & \\
\hline
\end{tabular}

Table 5 Results of Tukey's Post-Hoc Tests

\begin{tabular}{|c|c|c|c|c|c|c|}
\hline \multicolumn{7}{|l|}{ Tukey HSD } \\
\hline \multirow[t]{2}{*}{ (I) Groups } & \multirow[t]{2}{*}{ (J) Groups } & \multirow[t]{2}{*}{ Mean Difference (I-J) } & \multirow[t]{2}{*}{ Std. Error } & \multirow[t]{2}{*}{$\mathbf{p}$} & \multicolumn{2}{|c|}{ 95\% Confidence Interval } \\
\hline & & & & & Lower Bound & Upper Bound \\
\hline \multirow[t]{2}{*}{ RWL } & EAL & 0.09386 & 0.25502 & 0.928 & -0.5064 & 0.6941 \\
\hline & EALc & -0.03271 & 0.25502 & 0.991 & -0.6329 & 0.5675 \\
\hline \multirow[t]{2}{*}{ EAL } & RWL & -0.09386 & 0.25502 & 0.928 & $-0.694 I$ & 0.5064 \\
\hline & EALc & -0.12657 & 0.25502 & 0.873 & -0.7268 & 0.4737 \\
\hline \multirow[t]{2}{*}{ EALc } & RWL & $0.0327 \mid$ & 0.25502 & 0.991 & -0.5675 & 0.6329 \\
\hline & EAL & 0.12657 & 0.25502 & 0.873 & -0.4737 & 0.7268 \\
\hline
\end{tabular}


generation EAL has become a cornerstone since its introduction. $^{22,31}$ DentaPort $\mathrm{ZX}$, a third generation EAL, functions by measuring the quotient between the impedance of two different frequencies $(8 \mathrm{KHz}$ and $400 \mathrm{~Hz}$ ) in the canal. $^{31}$ An electrical current is passed from the EALs into the file inside the canal through a conductive attachment device to complete the circuit. $^{21}$

A few obstacles, such as blocked vision and a lack of space for the attachment device to reach the file shaft when using short files in posterior teeth, may be encountered by clinicians (Figure 1). ${ }^{25}$ Another problem is the pulling force of the attachment device, which may eliminate the tactile sensation; frequently, the device ends up totally inside of the tooth chamber. This force may also shorten the circuit in teeth restored with amalgam or metal crowns, resulting in a false-positive response due to the restoration's electrical conductivity.

Numerous companies have introduced new attachment devices, such as touching probes and file holders. ${ }^{26}$ These devices function by touching the file to complete the circuit. However, their lengths are not clinically effective, their metal shanks are relatively wide, the connection must occur in one direction only, they cannot be bent, and their costs may indicate that they cannot be widely used.

We adopted the Apexoconnection (EWLc), which is a clinical technique that aids the process of the root canal length determination by connecting the inserted file within the canal to the conventional attachment device via another endodontic file. This process helps overcome the above-listed obstacles (Figure 5). The concept behind the Apexoconnection technique is introduction of an ultrathin and flexible conductor, that of the endodontic file, to complete the apexlocator's electrical circuit. The recent EAL generations depends on alternating current of two or more frequencies and on generating impedance instead of resistance. ${ }^{21}$ This concept explains the hypothetical accuracy of the EALc technique since the resistance of an extra conductor (the endodontic file) will not interrupt the mechanism of recent EAL generations.

The aim of this study was to evaluate the accuracy of the WL determinations when using EWL and EWLc and comparing these determinations with the real WL (RWL), which was measured and recorded under a microscope. In the present study, a sample size of 118 canals (60 teeth) was measured, which is a much larger sample than those used in previous studies, to assess the accuracy of apex locators. ${ }^{2,11,17,22}$ The study results support the previous findings, which showed that the EWL results were comparable to RWL results. Plotino et al found that EWLc is a reliable method for WL determination within the $\pm 0.5 \mathrm{~mm}$ clinically accepted margin of error from the AC. ${ }^{22}$ An in vivo study has shown that no statistical difference between radiographic WL and WL determined by apex locators could be found. ${ }^{3}$ In addition, this study showed that both K- and NiTi files could be used with EWLs. In our study, the mean length of the EWLc was found to be more similar to the RWL length but without a statistically significant difference (Table 4). The mean lengths of RWL, EWL, and EWLc were 17.98, 17.88, and 18.01, respectively (Table 3).

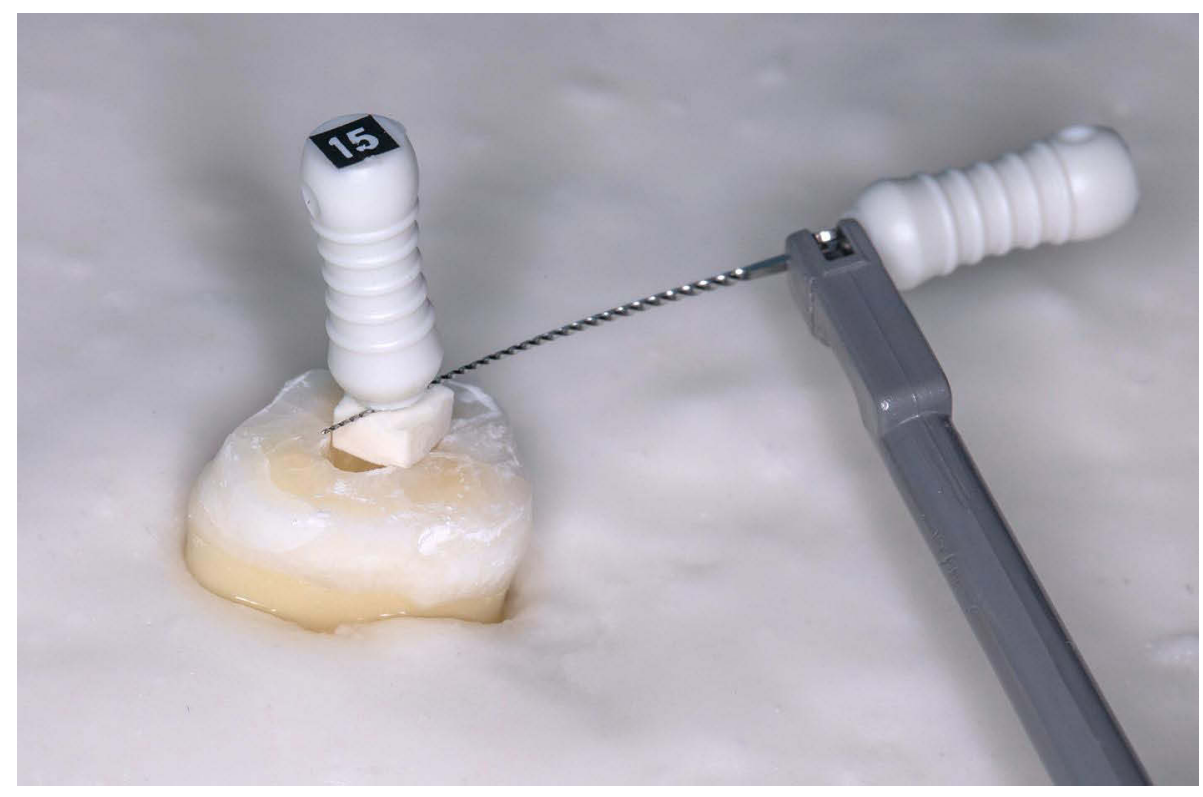

Figure 5 Apexoconnection technique shows clinical significance when limited space is available. 
As mentioned above, the pulling force of the conventional attachment device may be the reason for the shorter mean length in the EWL measurement. This finding may emphasize the clinical significance of using the Apexoconnection technique to determine WL conveniently in the least possible amount of time in daily practice.

Different embedding media, such as agar, alginate, and saline, have been used to simulate the clinical situation and to complete the electrical circuit. Alginate is a good electroconductive material, mimics the periodontal ligament, is easily prepared, and has low cost. ${ }^{8,30}$ These features made alginate the medium of choice as it is considered to be ideal for in vitro investigations. ${ }^{21,30,32}$

During length determinations, the examined teeth were irrigated with $\mathrm{NaOCl}$. It has been found that $\mathrm{NaOCl}$ is clinically safe and accurate when using EWLs in WL determination when compared to other solutions. ${ }^{20}$ To negotiate the canal to its terminus clinically, the EWL measurement is usually established with a small-size files. ${ }^{33}$ Thus, size \#8 stainless steel K-files were used to confirm the canal patency, size \#10 stainless steel K-files were used to establish the actual length of the canal, and size \#15 stainless steel K-files were used for determining the electronic working lengths of the canal in the present study. It was previously found that the accuracy of K-file sizes \#10,\#15, and \#20 are comparable and do not influence the electronic measurement with EWLs. ${ }^{10}$

The major limitation of this technique is the possibility of injury to the oral mucosa. This possibility can be avoided by cautiously placing a rubber dam or simply by placing a onesided rubber stopper at the connector file's tip. The study results need to be confirmed in an in vivo study since the control conditions are not available clinically and higher variables are expected in contrast to in vitro studies.

\section{Conclusion}

Under the conditions of this in vitro comparative study, no statistically significant difference was found between both techniques, and both revealed high accuracy in determining root canal length. Therefore, the Apexoconnection technique should be recommended in daily practice, not only because it efficiently determines WL, but also because its simplicity, convenience, and reliability.

\section{Abbreviations}

WL, working length; CDJ, junction of the dentin and the cementum; AC, apical constriction; EWL, conventional technique; EWLc, apexoconnection technique; $\mathrm{NaOCl}$, sodium hypochlorite; RL, actual length; RWL, real working length.

\section{Data Sharing Statement}

The data that support the findings of this study are available on request from the corresponding author.

\section{Acknowledgments}

The authors gratefully acknowledge the valuable comments from Dr. Deema Alshammery and Dr. Nasser Alqhtani, and the clinical support from Ms. Edgielyn Faldas. This research project was supported by a grant from the "Research Center at Riyadh Elm University".

\section{Disclosure}

Dr Muslat Bin Rubaia'an, Dr Mohammed AbuHassna, and Dr Rahaf AlShahrani are planning to obtain a patent inspired by this work. The authors report no other potential conflicts of interest at the time for this work.

\section{References}

1. Vier-Pelisser FV, Meng A, Netto LCB, Só MVR. Influence of the instrumentation technique and apical preparation diameter on calcium hydroxide filling in simulated curved canals. Indian J Dental Res. 2012;23(6):784. doi:10.4103/0970-9290.111260

2. Dinapadu S, Pasari S, Admala SR, Marukala NR, Gurram S, Peddi R. Accuracy of electronic apex locator in enlarged root canals with different root canal irrigants: an in vitro study. J Contemp Dent Pract. 2013;14(4):649. doi:10.5005/jp-journals-10024-1379

3. Chaudhary S, Gharti A, Adhikari B. An in vivo comparison of accuracy of two electronic apex locators in determining working length using stainless steel and nickel titanium files. Clin Cosmet Investig Dent. 2018;10:75. doi:10.2147/CCIDE.S158882

4. Golvankar K, Kader MA, Latheef AA, Ali ABM, Abullais SS, Sibagathullah M. Comparison of accuracy in determining the root canal working length by using two generations of apex locators-an in vitro study. Open Access Macedonian j Med Sci. 2019;7(19):3276. doi:10.3889/oamjms.2019.696

5. Ricucci D, Langeland K. Apical limit of root canal instrumentation and obturation, part 2. A histological study. Int Endod J. 1998;31 (6):394-409. doi:10.1046/j.1365-2591.1998.00183.x

6. Nekoofar M, Ghandi M, Hayes S, Dummer P. The fundamental operating principles of electronic root canal length measurement devices. Int Endod J. 2006;39(8):595-609. doi:10.1111/j.13652591.2006.01131.x

7. Burch JG, Hulen S. The relationship of the apical foramen to the anatomic apex of the tooth root. Oral Surg Oral Med Oral Pathol. 1972;34(2):262-268. doi:10.1016/0030-4220(72)90418-5

8. Saraswathi V, Kedia A, Purayil TP, Ballal V, Saini A. Comparative evaluation of the accuracy of two electronic apex locators in determining the working length in teeth with simulated apical root resorption: an in vitro study. J Conserv Dent. 2016;19(5):402-405. doi:10.4103/ 0972-0707.190002

9. Chugal NM, Clive JM, Spångberg LS. Endodontic infection: some biologic and treatment factors associated with outcome. Oral Surgery Oral Med Oral Pathol Oral Radiol Endodontol. 2003;96(1):81-90. doi:10.1016/S1079-2104(02)91703-8 
10. Cianconi L, Angotti V, Felici R, Conte G, Mancini M. Accuracy of three electronic apex locators compared with digital radiography: an ex vivo study. J Endod. 2010;36(12):2003-2007. doi:10.1016/j. joen.2010.08.036

11. Guise GM, Goodell GG, Imamura GM. In vitro comparison of three electronic apex locators. J Endod. 2010;36(2):279-281. doi:10.1016/ j.joen.2009.09.016

12. Karamifar K, Tondari A, Saghiri MA. Endodontic periapical lesion: an overview on the etiology, diagnosis and current treatment Modalities. Eur Endodontic J. 2020;5(2):54.

13. Seltzer S. Long-term radiographic and histological observations of endodontically treated teeth. $J$ Endod. 1999;25(12):818-822. doi:10.1016/S0099-2399(99)80305-7

14. Santhosh L, Raiththa P, Aswathanarayana S, Panchajanya S, Reddy JT, Susheela SR. Influence of root canal curvature on the accuracy of an electronic apex locator: an in vitro study. $J$ Conserv Dent. 2014;17(6):583-586. doi:10.4103/0972-0707.144610

15. Ravanshad S, Adl A, Anvar J. Effect of working length measurement by electronic apex locator or radiography on the adequacy of final working length: a randomized clinical trial. J Endod. 2010;36 (11):1753-1756. doi:10.1016/j.joen.2010.08.017

16. ElAyouti A, Weiger R, Löst C. Frequency of overinstrumentation with an acceptable radiographic working length. J Endod. 2001;27 (1):49-52. doi:10.1097/00004770-200101000-00018

17. ElAyouti A, Weiger R, Löst C. The ability of root ZX apex locator to reduce the frequency of overestimated radiographic working length. $J$ Endod. 2002;28(2):116-119. doi:10.1097/00004770-20020200000017

18. Vieyra J, Acosta J. Comparison of working length determination with radiographs and four electronic apex locators. Int Endod J. 2011;44 (6):510-518. doi:10.1111/j.1365-2591.2011.01855.x

19. Dummer PM, Mcginn JH, Rees DG. The position and topography of the apical canal constriction and apical foramen. Int Endod J. 1984;17(4):192-198. doi:10.1111/j.1365-2591.1984.tb00404.x

20. Khattak O, Raidullah E, Francis ML. A comparative assessment of the accuracy of electronic apex locator (Root ZX) in the presence of commonly used irrigating solutions. J Clin Exp Dent. 2014;6(1):e416. doi: $10.4317 /$ jced. 51230

21. Abdelsalam N, Hashem N. Impact of Apical patency on accuracy of electronic apex locators: in vitro study. $J$ Endod. 2020;46 (4):509-514. doi:10.1016/j.joen.2020.01.010
22. Plotino G, Grande N, Brigante L, Lesti B, Somma F. Ex vivo accuracy of three electronic apex locators: root ZX, elements diagnostic unit and apex locator and propex. Int Endod J. 2006;39 (5):408-414. doi:10.1111/j.1365-2591.2006.01095.x

23. Stein TJ, Corcoran JF. Radiographic "working length" revisited. Oral Surgery Oral Med Oral Pathol. 1992;74(6):796-800. doi:10.1016/ 0030-4220(92)90412-J

24. Hassanien EE, Hashem A, Chalfin H. Histomorphometric study of the root apex of mandibular premolar teeth: an attempt to correlate working length measured with electronic and radiograph methods to various anatomic positions in the apical portion of the canal. J Endod. 2008;34(4):408-412. doi:10.1016/j.joen.2007.12.013

25. Regan JE. Endodontic file with a metallic conductor as part of the plastic handle to facilitate use of electronic apex locators. Google Patents. 2005.

26. Langbein S, Storch R. Apex locator attachment. Google Patents. 2019.

27. Morita J, Corp K. DentaPort zx operation instructions. 2018.

28. Uğur Aydin Z, Göller Bulut D. Determination of root canal length up to perforation area using different electronic apex locators and cbct images obtained at different voxel sizes: a comparative ex vivo study. Chin J Dent Res. 2021;24(1):49-54. doi:10.3290/j.cjdr.b1105877

29. de Camargo EJ, Zapata RO, Medeiros PL, et al. Influence of preflaring on the accuracy of length determination with four electronic apex locators. J Endod. 2009;35(9):1300-1302. doi:10.1016/j.joen.2009.05.030

30. Baldi JV, Victorino FR, Bernardes RA, et al. Influence of embedding media on the assessment of electronic apex locators. $J$ Endod. 2007;33(4):476-479. doi:10.1016/j.joen.2006.12.024

31. Swapna DV, Krishna A, Patil AC, Rashmi K, Pai VS, Ranjini MA. Comparison of third generation versus fourth generation electronic apex locators in detecting apical constriction: an in vivo study. J Conserv Dent. 2015;18(4):288-291. doi:10.4103/0972-0707. 159726

32. Guerreiro-Tanomaru JM, Croti HR, Silva GF, Faria G, TanomaruFilho M. Tooth embedding medium influences the accuracy of electronic apex locator. Acta Odontol Latinoam. 2012;25(2):214-217.

33. Ebrahim AK, Yoshioka T, Kobayashi C, Suda H. The effects of file size, sodium hypochlorite and blood on the accuracy of Root ZX apex locator in enlarged root canals: an in vitro study. Aust Dent J. 2006;51(2):153-157. doi:10.1111/j.1834-7819.2006.tb00419.x
Clinical, Cosmetic and Investigational Dentistry

\section{Publish your work in this journal}

Clinical, Cosmetic and Investigational Dentistry is an international, peer-reviewed, open access, online journal focusing on the latest clinical and experimental research in dentistry with specific emphasis on cosmetic interventions. Innovative developments in dental materials, techniques and devices that improve outcomes and patient satisfaction and preference will be highlighted. The manuscript management system is completely online and includes a very quick and fair peer-review system, which is all easy to use. Visit http://www.dovepress.com/testimonials.php to read real quotes from published authors. 